\title{
A Study on Rongmei Syllable Structure
}

\author{
Debajit Deb \\ Department. of Linguistics, Rabindranath Tagore School of Languages and Cultural Studies, Assam University, \\ Silchar, Assam. India
}

\begin{abstract}
A syllable is a sound or succession of a sounds uttered within a single breath-impulse. Syllable is a unit of pronunciation consisting of a vowel alone or of a vowel with one or more consonants. Phonologically, the syllable is "a unit containing one and only one vowel either alone or surrounded by consonants in certain arrangements". (O'Connor 1973). It is generally accepted that nucleus is obligatory in all languages, thus, the same is true in case of Rongmei. Rongmei is one of the schedule tribe of Northeast India, mainly concentrated in Assam (Barak Valley), Manipur and Nagaland. Ethnically, Rongmeis are Mongloids and their language belongs to Kuki-Naga section of the Kamarupan group of the Baric sub-division of Tibeto-Burman family of languages (Matisoff, 2001). The analysis indicates that Rongmei treats both onset and coda as optional. Besides, the clustering phenomenon is absent at both onset position coda position. This paper is an effort to look into the possible syllable structure in Rongmei Naga language spoken in Barak Valley of South Assam.
\end{abstract}

Keywords: Syllable, Syllable Tree, Heavy Syllable, Light Syllable, Syllable Structure,

DOI: $10.7176 / J L L L / 56-07$

Publication date:May $31^{\text {st }} 2019$

\section{Introduction}

According to Catford (1988), the syllable is defined "as a minimal pulse of initiatory activity bounded by a momentary retardation of the initiator, either self imposed, or more usually, imposed by a consonant type of articulatory stricture". Ladefoged (2000), contends that there is no satisfactory definition for this unit of speech, but that syllables seem to be necessary units in the mental organization and production of utterances. However, Crystal defines (1987) the syllable as an element of speech that acts as a unit of rhythm, consisting of a vowel, syllabic, or vowel/consonant combination.

A sequence of phonemes with one peak of sonority is called a syllable. Being the higher unit than the speech sound (i.e. phoneme), the syllable is made up of one or more than one speech sound. Speech sounds are either vowels or consonants. The vowel element is essential to the structure of a syllable; that is, a syllable is not possible without the vowel element. So, the vowel element being obligatory, if a syllable consists of only one sound, the sound will be a vowel. For example, the Rongmei syllables /ai/ consists of one vowel i.e., diphthong. If a syllable consists of more than one sound, one of them must be a vowel and the other one is the consonant. The vowel obviously is the obligatory element in a syllable and is called its rhyme. The onset is the first or initial part of a syllable, the middle part is rhyme and the last part is called coda. The rhyme also called the core and nucleus, the peak of the syllable. The rhyme is further divided into nucleus and coda shown in the fig. 1:

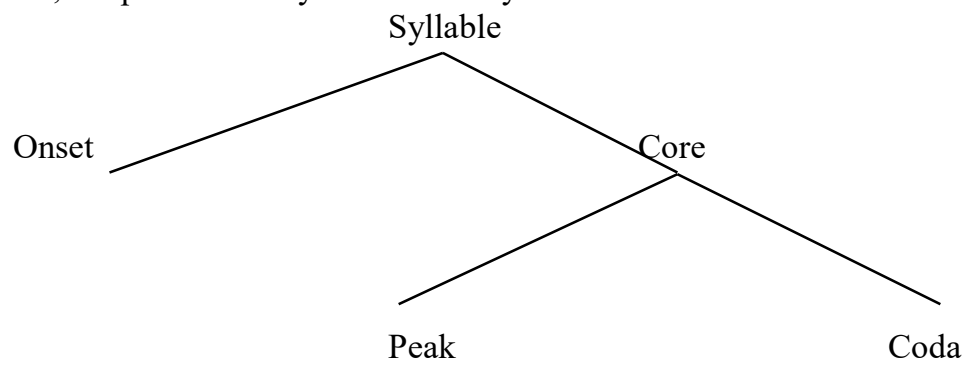

A syllable consists of a vocalic nucleus and attached consonants and carries an obligatory tone. The consonant on the other hand, occupies a marginal place in a syllable or a word. The consonant which begins a syllable is called the releasing consonant, and that which occurs at the end of a syllable is called arresting consonant. In the syllable $/ \mathrm{lim} /$, for instance, $/ \mathrm{l} /$ is the releasing consonant and $/ \mathrm{i} /$ is the nucleus and $/ \mathrm{m} / \mathrm{the}$ arresting consonant. A syllable can be open or closed depending on whether the syllable ends in a consonant or a vowel. An open syllable is on which ends in a vowel, opposed to closed syllable, which ends in a consonant. This feature is sometime referred to as free syllable. The open syllable is the first syllable type to be productively used by children, in the early stage of phonological development. The following fig:2 is the phonologic diagram of speech syllable proposed by Crissov (2010). 


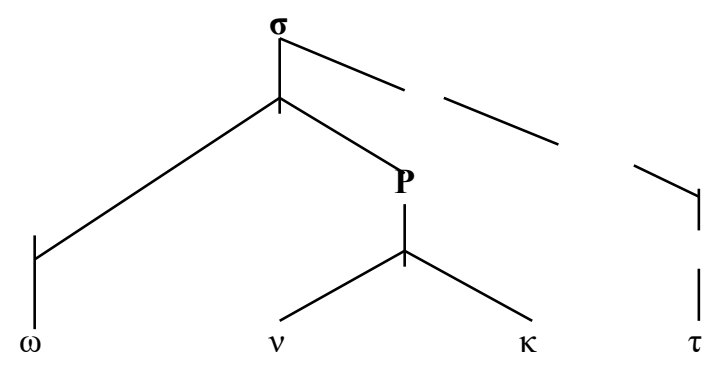

Fig 2: $(\sigma)$, split into rime $(\rho)$, onset $(\omega)$, nucleus $(v)$, coda $(\kappa)$ and tone $(\tau)$

Here if the the syllables are ending with a vowel considered light syllable while the consonant ending as well as diphthongal syllables, i.e., the syllable where the coda is present and those in which the peak branches are considered 'heavy' e.g. /ti/ 'give' /pu/ 'father' /ga/ 'crab' are light syllable while /in/ 'a small fishing net' /dui / 'water' /gən/ 'curry' /oin/ 'rule' etc are all heavy syllable.

Heavy Syllable:
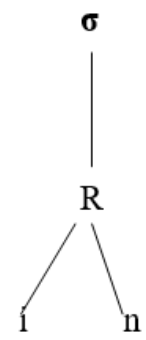
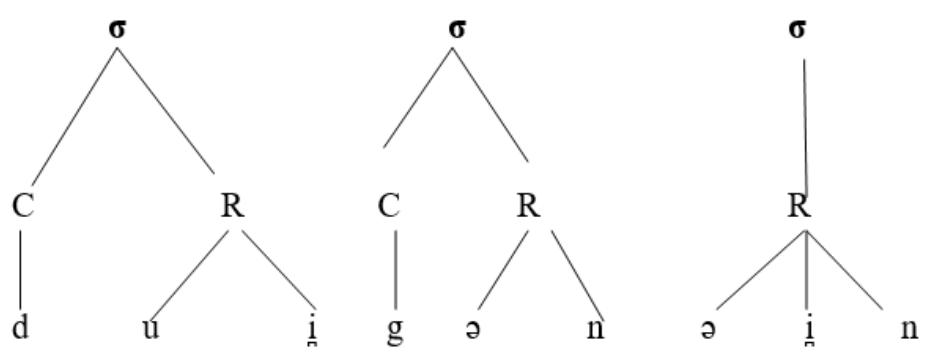

Light Syllable:
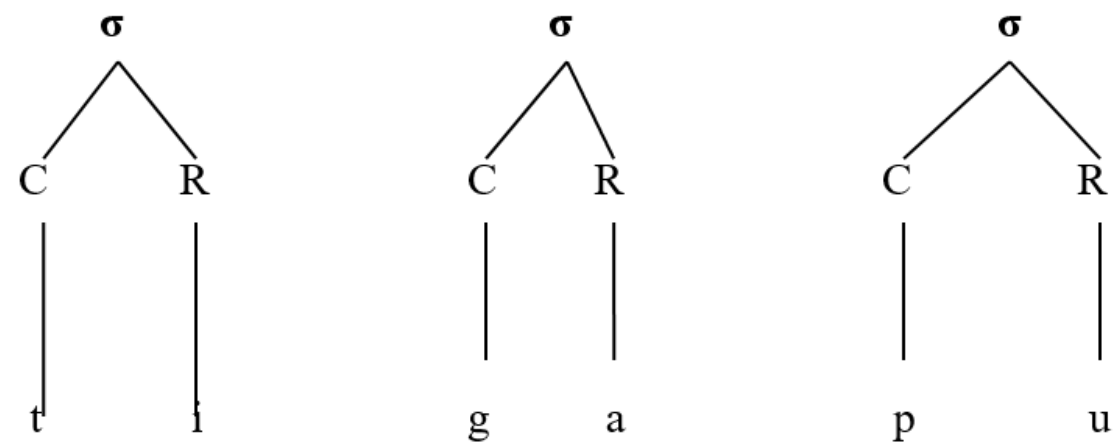

A word consists of one or more than one syllable in Rongmei. In case of most words, it should comparatively easy to point out how many syllables a given word has. For example, it is not difficult to identify the syllables in the Rongmei words $p i$ 'father', alau 'child' akaina 'younger sister' inkhenglaumai 'patient' riangrisumai 'guat' and say that they contain one, two, three, four and five syllables respectively. The pronunciations of these words in phonemic transcription are: /pi/, /al-áu/ /a'-kai-na/ /ín-k $k^{\mathrm{h} e \eta-l a ́ u-m a ́ i / ~ / r i ́-a n-r i ̀ u-~}$ sú-mai/. It will be clear from these words (the syllable division is marked with a hyphen in each case) that the number of syllables in each corresponds to the number of vowel sounds i.e., vowel phonemes it contains. It must be remembered here that the $a i$, au (diphthongs) are the single vowel phonemes. This is one of the simple rules of dividing words into syllables.

\section{Review of Literature}

There are not many linguistic studies on Tai Khamti. The following are the major linguistics works found in the language that includes: 1) Grierson, G.A. (ed.). (1903-28). Linguistic Survey of India Vol. III part II, 2) Shreedhar (1979) Phonemes of Rongmei, in Indian Linguistics, Vol. 40, No.1 3) G. Makuga. (1994). Introduction to Rongmei Naga J.M. Printing Works. Imphal 4) Neihlalung.K.G. (2008) Pacgaymeilat. Published by: Rongmei Literature Committee, Assam. Neither of these works emphasize on Syllable structure. Hence the proposed study is indispensable to focus on the syllable structure of Rongmei Naga

\section{Methodology}

For the present study the data have been collected during my field work on $20^{\text {th }}-28^{\text {th }}$ October, 2012 and 16 th $25^{\text {th }}$ December 2012, from the Rongmei community, living in Catcher District of Kalabil Rongmei Naga Punji, 
Kaguailuang (Phatokbazzar) Silchar, Atira (Shingirbond) and Hailakandi (Pantiluang) Rongmei Naga Punji. The data has been collected by asking the native speakers of Rongmei to prepare the list of words that they commonly use in their real life. In order to work out the syllabification patterns, the participants were asked to pronounce the words from the prepared list. People from the different age groups including both the sexes were surveyed for this study

\section{Syllable Structure}

Spencer (1996) stated that, "Syllable structure plays an important role in the organization of the phonological processes of a language. This often occurs through the operation of syllabically based phonotactic constraints". The phonotactic meaning is, the way in which sounds are arranged or ordered. In Rongmei language the maximum number of syllables in a word is six but their occurrence is very limited in the language same construction can also be possible in her sister languages like Liangmai and Zeme Naga. Most of the words are monosyllabic in nature. Most syllables have an onset. Some languages restrict onsets to be only a single consonant, while others allow multi-consonant onsets according to various rules. For example, in Rongmei, onset such as pr-, pl-,kr-, and many others can be possible but in Rongmei only single onset is so far found. On the basis of recorded data the basic structure of Rongmei syllables are VC, VV, CV, CVC, VVC. Given below are the different types of syllables that we have in Rongmei.

\subsection{Mono-syllabic Words:}

Rongmei roots are generally of monosyllabic type. The majority of the monosyllabic words have the CV pattern, but the monosyllabic words having VC pattern have extremely low frequency of occurrence. It is also observed that Rongmei word consists only of a vowel i.e., diphthong as exemplified below. Here the symbol $\mathrm{V}$ and $\mathrm{C}$ represents the vowels and the consonants respectively. Hear VV $\square$ stands for diphthongs where the $2^{\text {nd }} \mathrm{V}$ is always a non-syllabic semi vowel.

\begin{tabular}{|l|l|l|}
\hline $\mathrm{V} \underline{\mathrm{V}}$ & /ái/ & 'I' \\
\hline $\mathrm{VC}$ & /in/ & 'a small fishing net' \\
\hline $\mathrm{CV}$ & /bi/ & 'clay' \\
\hline $\mathrm{CV} \underline{\mathrm{V}}$ & /páu/ & 'grandfather' \\
\hline $\mathrm{CVC}$ & /gín/ & 'guest' \\
\hline
\end{tabular}

\subsection{Di-syllabic Words:}

4.2.1.The second syllable is opened:

\begin{tabular}{|c|c|c|}
\hline CVCV & /pə-ri/ & 'story' \\
\hline CVCVV & /b`o-mái/ & 'mad' \\
\hline CVVCVV & /lui-mái/ & 'massage' \\
\hline CVECVV & /sái-láu/ & 'desert' \\
\hline
\end{tabular}

\subsubsection{The second syllable is closed:}

\begin{tabular}{|l|l|l|}
\hline CVCCVC & /lo'y-pan/ & 'cotton' \\
\hline CVVCVC & /mái-dat/ & 'indifferent' \\
\hline CVVC & /pu-ən/ & 'air' \\
\hline CVCCVC & /lún-nìn/ & 'mind' \\
\hline CVCVC & /ká-pèk/ & 'flat' \\
\hline
\end{tabular}

\subsection{Tri-syllabic Words:}

4.3.1.The third syllable is opened:

\begin{tabular}{|c|c|c|}
\hline VCVㅌV & /á-tau-pù/ & 'grandson' \\
\hline VCV $\underline{\bar{V} C V}$ & /o'-kai-na/ & $\begin{array}{l}\text { 'younger sister } \\
\text { or brother' }\end{array}$ \\
\hline CVㄷCCV믈 & /nái-lìm-mai/ & 'shade' \\
\hline CVVCCV $\underline{V}$ & /bí-an-mai/ & 'slope' \\
\hline CVVCVCV & /rui-gú-na/ & $\begin{array}{l}\text { 'a kind of green } \\
\text { snake' }\end{array}$ \\
\hline
\end{tabular}


4.3.2. The third syllable is closed:

\begin{tabular}{|l|l|l|}
\hline CVCVVC & /kə-k ${ }^{\text {hú-an/ }}$ & 'sound' \\
\hline CVㄷCVC & /mái-la-báy/ & 'abdomen' \\
\hline CVCCVCCVC & /zəm-pín-but/ & 'coward' \\
\hline CVCCVCVC & /d`ən-di-báy/ & 'sword' \\
\hline CVㄷCVVC & /t'áu-tú-ay/ & 'whose' \\
\hline
\end{tabular}

\subsection{Tetra-syllabic Words.}

4.4.1. The fourth syllable is opened:

\begin{tabular}{|l|l|l|}
\hline CVCCVCCVCV $\underline{V}$ & /də'k-də'k-nə-pai/ & 'bird smaller than sparrow' \\
\hline VCCVCCV $\underline{V} V \underline{V}$ & /inn-k'en-láu-mái/ & 'patient' \\
\hline CVCCVVCCV & /lìm-čú-ay-na/ & 'star' \\
\hline CVVCCVCV $\underline{V}$ & /dì-án-nə-mái/ & 'boxing' \\
\hline
\end{tabular}

\subsubsection{The fourth syllable is closed:}

\begin{tabular}{|c|c|c|}
\hline VCVㄷVVC & /a'-nìu-tu-áy/ & 'us' \\
\hline CVCVVCVVC & /tə-ráu-lu-án/ & 'grave' \\
\hline CV드므CVCV & /dùi-lúi-ka-máy/ & 'leopard' \\
\hline
\end{tabular}

\section{Sesquisyllabic word:}

There are some pronominal prefixes in Rongmei like $a-, n a$ - and $-k a$. The prefix $\partial-$, the first person pronominal prefix which expresses possessive when occurring with nominal bound roots. This prefix $\partial$ - in Rongmei occurs with kinship terms that refer to both older and younger ones. The usage of prefix $\partial$ - is restricted to kinship terms, body parts, plants and natural objects as in: a-pui 'my mother' o-pi 'my head' $a-k a i$ 'my house' Like first person pronominal prefix 2 -, the second person pronominal prefix $n a$ - occurs with bound nominal roots particularly the kinship terms body parts and natural objects for instances: na-pui 'your mother' na-sa?m 'your hair' na-nam 'your village' the third prefix is $k a$ - like other pronominal prefixes, the third person pronominal prefixes $k a-$ expresses possessive and occurs inherently with kinship terms, with body parts and natural objects for examples: ka-pui 'his/her mother' ka-zau 'his/her face' ka-tau 'his/her stone'.

Matisoff (1973) called this $a$ - prefix, a vocative of kinship terms and noted that it is widespread in TB languages and Chinese, as well. Kinship terms with the minor initial $a$-syllable are also well attested in Burmese (Okell 1969:99). It is interesting to note that the prefix $a$-itself is a minor syllable attached to the kinship term and it forms a sesquisyllabic word, the term coined by (Matisoff, 2003). In this connection Post (2007) also made the similar statement in describing Galo language that there are three different minor syllables $(a, n a$, and $s a)$ which attach to kinship terms and thus form sesquisyllabic words. The kinship terms with $a$ - minor syllable are well attested, cross-linguistically, among many Tibeto-Burman languages.

\section{Conclusion}

A syllable is a rhythmic unit of speech. Syllables exist to make the speech stream easier for the human mind to process. A syllable comprises one or more segments; segments are the building blocks for syllables. Thus on the basis of the above discussion it can be concluded that:

i) All the Rongmei words are made of syllables. Each syllabe carries an obligatory tone.

ii) Generally, Rongmei roots are of monosyllabic type, for instance, even a vowel can be a syllable or a morpheme or a word in the language. It is also observed that bisyllabic roots are also frequently found in the language where as the occurance of tri and tetra-syllabic words are very less in the language.

iii) A syllable in the CV canonical form is called a light syllable and a syllable in CV $\underline{V}$ or CVC canonical form is called a heavy syllable.

iv) The most commonly used syllable pattern in Rongmei is CVC. This pattern is also frequently used by Liangmai and Zeme Naga groups.

v) In Rongmei, as in other Tibeto-Burman languages the syllabic splitting depends mainly on the foregoing and the following environments of the syllable peak.

vi) The presence of sesquisyllabic words are also noticed in the language.

\section{Reference}

1) ) Crystal, D. 1980. A Dictionary of Linguistic and Phonetics. London: Basil Blackwell.

2) Catford, J.C. 1988. A Practical Introduction to Phonetics. New York: Oxford University Press.

3) Deb,Debojit. 2010. The Phonology of Rongmei Naga. Unpublished M.Phil.Dissertation. Dept. of Linguistics. Assam University, Silchar. 
4) Duanmu, S. 2008. Syllable structure. New York: Oxford University Press.

5) Haroon-ur-Rashid \& Sohail Ayesha. 2012. "An Introduction to Hindko Syllable Typology"

. Language in India. Volume 12: 2 February ISSN 1930-2940.

6) Kom,K. T. 2009. A Description of the Kom Speech with Special Emphasis on Variation. Unpublished Ph.D. thesis. Dept. of Linguistics, NEHU Shillong.

7) Ladefoged, P. 2001. A course in phonetics. USA: Harcourt College Publisher.

8) Matisoff, J.A. 2001. Prosodic Diffusibility in South-East Asia. In: Areal Diffusion and Genetic Inheritance. A.Y. Aikhenvald \& R M W Dixon (eds.)

9) Matisoff, James A. 2003. Handbook of Proto-Tibeto-Burman. Berkley, University of California Press.

10) O Connor, J. D. 1973. Phonetics. Harmondsworth, Middlesex: Penguin Books.

11) Okell, J. 1969. A Reference Grammar of Colloquial Burmese. London, Oxford University Press.

12) Post, Mark William. 2007. A grammar of Galo. Ph.D Dissertation, Melbourne, LaTrobe University. . (in press). Galo Negation and the Reconstruction of Proto-Tani Predicate Syntax: Explaining a Typological "oddity” in diachronic Terms, South Asian Language Review 20(1).

13) Spencer, Andrew. 1996. Phonology: Theory \& Description. Blackwell Publisher.

14) Crissov. 2010. Phonologic diagram of speech syllable. https://commons wikimedia.org /wiki/File:Syllable_diagram.png

Acknowledgement

I owe a great deal of gratitude to my informants Mr Abijan Rongmei and Haron Kamei for their encouragement and cooperation during my field work. I sincerely acknowledge to my supervisor Dr. Kh. Dhiren Singha, who helped, encouraged me for the successful completion of this work. Finally, my sincere thanks go to the editor and the reviewers of this prestigious journal for their valuable comments and suggestions. 